\title{
Modeling the limitations and implicit costs of cereal self-sufficiency: the case of Morocco
}

\author{
Nicholas Magnan • Travis J. Lybbert • \\ Alex F. McCalla $\cdot$ Julian A. Lampietti
}

Received: 3 September 2010 /Accepted: 30 November 2010/Published online: 10 February 2011

(C) The Author(s) 2010. This article is published with open access at Springerlink.com

\begin{abstract}
High and volatile food prices in 2008 have led to renewed interest in national food security, particularly in the Arab world. One often discussed strategy is to reduce import dependency by increasing self-sufficiency. An alternative strategy is agricultural self-reliance, where revenues from export crops are sufficient to cover the costs of food imports. For countries with limited land and water resources and a comparative advantage in producing export crops rather than cereals, self-reliance (achieving food security through trade) may be more effective than aiming for self-sufficiency in cereals. This paper uses a simple model based on a production possibilities frontier to demonstrate the limitations and high costs of achieving self-sufficiency in cereals for Morocco. At current yield levels, Morocco is capable of achieving $85 \%$ selfsufficiency. With a $30 \%$ increase in yields the country could achieve self-sufficiency in the present, and with a $40 \%$ increase, achieve self-sufficiency until 2022. However, this would require land to be diverted from high value crops
\end{abstract}

\section{N. Magnan $(\square)$}

Environment and Production Technology Division,

International Food Policy Research Institute,

2033 K Street, NW,

Washington, DC, USA

e-mail: n.magnan@cgiar.org

\section{T. J. Lybbert • A. F. McCalla}

Department of Agricultural and Resource Economics,

University of California, Davis,

1 Shields Avenue,

Davis, CA 95616, USA

\section{J. A. Lampietti}

Sustainable Development Department,

Middle East and North Africa Region, World Bank,

1818 H Street, NW,

Washington, DC 20433, USA to cereals, with an opportunity cost exceeding US\$10.3 billion in gross revenue during the period 2008-2022. Morocco and other Arab countries should consider these factors when they asses whether self-sufficiency is a reasonable policy objective, or whether self-reliance would be more appropriate. The model requires only very basic data, uses a simple maximization routine, and can be easily replicated in a wide variety of contexts.

Keywords Food security · Self-sufficiency · Morocco $\cdot$ Food price shock $\cdot$ Agricultural trade

\section{Introduction}

Rising food prices, dwindling grain stocks, and concerns about physical shortages of staples have raised issues of food security to the top of many national agendas. In countries that depend on international markets for a significant share of their basic food supply, selfsufficiency is being suggested as a policy objective. Historically, national food self-sufficiency has been equated with food security, but the definition could also be expanded to include agricultural self-reliance (Panagariya 2002). National food security is achieved when all citizens are individually food secure; but this is less straightforward than it appears. For Robinson Crusoe, food security equaled self-sufficiency. For nations integrated into the world economy, food security is more complicated and involves trade-offs and choices.

Nations often talk of self-sufficiency ratios (the proportion of domestic consumption obtained from domestic production) as a measure of food security. A ratio of 1 or more would imply that the country's production satisfies all its food consumption needs. While this may occur for 
particular commodities, it is almost never possible for a country to be fully self-sufficient. Pending a counterfactual, let us assert that no country is agriculturally self-sufficient, i.e. no country produces all its own food. Agricultural selfsufficiency in a commodity may be possible but not always desirable. A related concept often used is agricultural selfreliance, where agricultural exports generate sufficient foreign exchange to pay for agricultural imports. For countries with limited land and water resources and a comparative advantage in producing export crops, aiming for agricultural self-reliance will get the country closer to the broadened definition of food security than aiming for self-sufficiency in cereals, which may be impossible to begin with. Neverthelss, countries worldwide are shifting their policy goals from food security to food selfsufficiency (Anon. 2009a, b). The objective of this paper is to shed some light on the limits of cereal self-sufficiency, and the implicit cost involved in attempting to reach selfsufficiency. To this end we present a model that captures the tradeoffs between cereal production and high value crop (HVC) production at a national level. Understanding this tradeoff is important as countries begin to rethink national food production and food security policies against a background of increasing and volatile international prices and growing domestic demand.

Modeling food security tradeoffs at national level is difficult, especially in developing countries where farmers are extremely heterogeneous and data are limited. In this paper we describe an approach we have devised to do this, and apply it to Morocco. Morocco is a cereal producer and a net cereal importer that has a comparative advantage in HVC production compared to potential trade partners like the European Union (EU), USA, Canada, Australia, Argentina, and Ukraine. Our approach can be refined and replicated in other countries. To ensure general replicability, we use production data by crop and by province, which are generally collected by national ministries of agriculture and are widely available. The model can easily be calibrated with the data available, and used in a variety of contexts. The model will be used to examine (i) how a potential increase in irrigated land that would allow for additional HVC production would change the tradeoff between cereal and HVC production, (ii) how a cereal price shock could change optimal national cereal versus HVC output, (iii) the limitations and cost of cereal selfsufficiency in the face of growing consumer demand.

\section{The model}

A national production possibilities frontier

This approach is based on the simple concept of a production possibilities frontier (PPF). Such a frontier is literally a map of production tradeoffs. To trace out a PPF between cereal and HVC production we calculate the maximum value of total agricultural production (HVCs and cereal) for different levels of cereal production, by cultivated area. At each level of cereal cultivation, a social planner examines yields of different crops in different provinces, as well as prices, to determine what to plant where in order to maximize national value of production. Because the model is treated as if solved by a social planner at the national level, as opposed to many disaggregated farmers, it overlooks many of the incentives and barriers that determine land allocation decisions at the farm level, such as access to markets (inputs, credits, marketing chains, etc.). With the available data, it is not possible to solve this problem at the farm level, so we need to place limitations on the model that will prevent the optimization model from finding unrealistic solutions. To ensure the model only uses realistic aggregate land allocations at the province level we create an upper bound using the historical maxima of land allocated to each crop type.

Once constructed, the model uses simple linear programming methods and can be solved using widely available software packages (Microsoft Excel Solver, MATLAB, GAMS, GAUSS, SAS, STATA, etc.). We then use optimal values obtained from the optimization routine to trace a PPF and use an elasticity measure to capture the slope of this frontier to characterize HVC-cereal tradeoffs in Morocco. We employ three candidate simulations to illustrate how the model can help address relevant policy questions. These simulations do not aim to rigorously assess policy impacts, but to demonstrate how the notion of a tradeoff gradient as manifest in a PPF might be useful to motivate policy discussions and more sophisticated policy modeling. For countries that wish to initiate a dialog about national food security policy and the limitations of selfsufficiency, such a feasible and relatively simple modeling exercise may serve as a useful point of departure.

\section{Data}

Crops

The model is constructed using province-level data on harvested area and productivity for 29 crops, for the period 1994 to 2003. These data are collected annually by the Moroccan Ministry of Agriculture. Before using the data to construct an optimal crop allocation model, we first cluster crops into categories. This simplifies the tradeoff space while still treating crops with substantially different production features as different crops. Specifically, we cluster the 29 crops into seven categories further divided into two crop groups (Table 1). Cereal crops, legume crops, forage crops, and fallow land are combined into a cereal 
Table 1 Crop groups (1), crop categories (2), and crops (3)

\begin{tabular}{|c|c|c|c|c|c|c|c|}
\hline \multirow{2}{*}{$\begin{array}{l}1 \\
2\end{array}$} & \multicolumn{3}{|c|}{ Cereal rotation crop group } & \multicolumn{4}{|c|}{ High value crop (HVC) group } \\
\hline & Cereal & Legumes & Forage & Fruit & Truck & Nut/Oil & Sugar \\
\hline \multirow[t]{6}{*}{3} & Durum wheat & Beans & Oats & Citrus & Onion & Almond & Beet \\
\hline & Soft wheat & Lentil & Corn & Date & Potato & Peanut & Sugarcane \\
\hline & Barley & Orobe & Sorghum & Grape & Tomato & Olive & \\
\hline & Rice & Peas & Other forage crops & Other fruits & Other truck crops & Sunflower & \\
\hline & & Chickpea & & & & Other industrial crops & \\
\hline & & Other legumes & & & & & \\
\hline
\end{tabular}

rotation group, since these are commonly cultivated in rotation as they exhibit intertemporal complementarities in terms of nutrient use (Ryan et al. 2008).

\section{Land}

Crop-specific land constraints for each province are essential to the model. The PPF cannot be estimated from production functions due to the complexity of highly heterogeneous agricultural systems and lack of data. By constraining land use to historical maxima we ensure realistic production boundaries while allowing for tradeoffs between crop categories. This approach to constraining production is easily replicable for all countries, even with minimal data.

In Morocco, growth in cereal productivity is projected to come entirely from intensification, not expansion (IFPRI 2008). Production increases in Syria, Libya, and Iraq are also projected to come at least $75 \%$ from intensification. In contrast, production increases in Jordan and Lebanon are expected to come at least $50 \%$ from land expansion, with other countries in the region falling somewhere in between. Therefore, cultivable land, i.e. either irrigated land or land where rainfall is sufficient to grow crops, is the primarily time-invariant limiting constraint. Consequently, the combination of land and water is the main limiting factor. Since water outcomes are determined after crop decisions are made in any given year, and water cannot be transferred from one crop to another after fields are planted, we use cultivable land as the constraint in our model. The overlap between cereal and HVC land is complicated and not typically observable to the researcher. Some land in a given province might be suitable for cereals but not HVCs, and land suitable for one HVC may not be suitable for another. In this model we assume all cultivable land can be used for cereals.

The potential to irrigate land has a large impact on what crops can be grown. Most cereal production in Morocco is rainfed, and most HVC production is irrigated. This relationship, however, is not exact. Between 10 and $20 \%$ of cereal is grown on irrigated land, and $25 \%$ of permanent crops are rainfed (AOAD 2008; IFPRI 2008). However, some of the crops considered to be high value are annual crops (truck crops, oilseeds, some nuts, and some fruits). The data confirm that there is only a loose correlation between the percentages of land planted in specific crop categories and the percentage of irrigated land in a province (Table 2).

Researchers at the Moroccan Institut National de la Recherche Agronomique (INRA) are developing a methodology to map out land by productive potential for different crops (Mohamed Badraoui, personal communication, June 2009), but until this massive project is completed another method is required to impose limitations within the model on what can be planted where. For each province, the maximum cultivable area for each HVC category is therefore proxied with historical maxima. The total amount of agricultural land available in each province is also

Table 2 Correlation of cultivated area $^{\mathrm{a}}$ with $\%$ of land irrigated ${ }^{\mathrm{b}}$

\begin{tabular}{|c|c|c|c|}
\hline \multicolumn{2}{|c|}{ Cereal rotation group } & \multicolumn{2}{|l|}{ HVC group } \\
\hline Crop category & Positive/negative correlation with\% of land irrigated (1996) & Crop category & Correlation with $\%$ of land irrigated (1996) \\
\hline Cereal & $-8.6 \%$ & Fruit & $61.4 \%$ \\
\hline Legumes & $-25.9 \%$ & Nuts and oil crops & $0.0 \%$ \\
\hline Fallow & $-6.0 \%$ & Sugar & $2.5 \%$ \\
\hline Forage & $19.6 \%$ & Truck crops & $18.3 \%$ \\
\hline
\end{tabular}

${ }^{\text {a }}$ Cultivated area data taken from 1996 to 1998 to best correspond with National Agricultural Survey data

${ }^{\mathrm{b}}$ Irrigation data from 1996 National Agricultural Survey (most recent published data) 
constrained by historical maxima, and the sum of crop by crop maxima is greater than the total land area maximum in each province, indicating some overlap in land use across years. The proportion of land allocated to each crop in the cereal rotation group is kept constant in each province at the 1994-2003 mean. This does not allow for adjustments within cereal rotation crop group, and assumes that the rotations farmers use are strategic (i.e. utility maximizing). Some components, most notably fallow, are necessary for the success and sustainability of the system although they do not increase short-run profits in the model. Likewise, the proportion of land planted to nuts and oil crops is held constant at the mean proportion within each province, to simplify the optimization routine. Among HVC crops, nuts and oils are most similar in terms of price and yield. The model allows the user to relax constraints on land allocation for different crop categories. For instance, constraints can be relaxed by allowing for conversion of cereal land to HVC production.

\section{Yields}

Crop-specific yields by province play a central role in the model: the optimal crop area allocation hinges on differences in productivity across provinces, as this is the most disaggregated data available. We explored many approaches to estimating crop-specific yield by province. Regression analysis using different combinations of rainfall and a time trend variable resulted in wildly varying (and often highly inflated) predicted yields, particularly for HVCs. These regressions, in many forms, yielded unsatisfactory results with poor predictive power. The only consistent trend was that cereal yields depend on rainfall, while HVC yields generally do not, which is likely considering the prevalence of rainfed cereal and irrigated HVCs in Morocco. Although it is tempting to use regression coefficients to control for rainfall and a time trend variable to project yields from the most recent data point (2003) to the present, results were discouraging. Therefore we used the median province yield by crop from 1994 to 2003, to eliminate outliers.

We aggregate yields in each province into average crop category yields by year, weighted by area harvested in the province as a proportion of total area harvested in the crop category. The model can easily be modified by changing these baseline yields at the crop and province level to account for increases in productive efficiency as projected by local researchers.

\section{Prices}

For the model, 2005 national prices from Moroccan Ministry of Agriculture data are used. Prices are taken at the crop category level (i.e. the weighted average price of fruits, rather than the prices of individual fruits). The model is sufficiently transparent that any set of prices (averages over several years, projected prices, international prices, etc.) could easily be used to reflect changing market conditions or price supports and other policy changes.

Morocco has a long-standing producer and consumer subsidy for soft wheat production. Subsidized wheat is purchased at 2600 Dirham per tonne and is used to make subsidized bread, which remains at a constant price of 1.20 Dirham per loaf, even as world food prices fluctuate (Fédéraion de Negociants en Cereales, personal communication, June 2009). However, between two-thirds and fourfifths of soft wheat production is not marketed through official channels: it is sold at free market prices that are not directly affected by the subsidy, but may be indirectly affected, as subsidized and unsubsidized wheat are substitute goods (Azzam 1991).

The subsidized price of wheat is incorporated into the weighted cereal price assuming that $37 \%$ of cereal cultivation (excluding forage) is soft wheat (Moroccan Ministry of Agriculture) and that 25\% of soft wheat produced is sold at the subsidized price, based on historical and current estimates (Azzam 1991). The end result is a 3\% increase in the price of cereals from the market price, which we consider to be the import price (FAOStat 2009). This seemingly small difference between the subsidized and unsubsidized cereal price will not change the optimal solution to the maximization problem. The $3 \%$ difference in weighted cereal price, however, is not included in total value of production as it is artificially infused by the government. Likewise, this subsidy results in substantial costs to the government which we report with our simulation results, where appropriate.

\section{Maximization problem}

The maximization routine embedded in the model is static. This routine maximizes the single year gross national value of total crop production subject to the province- and cropspecific land constraints discussed in the previous section. There is a total of $39 \times 4$ choice variables representing the land allocated to each crop category in each province. These variables are bounded by the maximum land ever allocated to that crop category in a given province. The land under cereal is the residual land in the province, ensuring all cultivable land is used. The maximization routine delivers the total amount of land in each crop category by province, and disaggregated output for each component of the cereal system and the nuts and oil category. These acreages are then multiplied by national prices and provincial average yields to give production and value for each province, as well as nationally. 
The maximization problem can be written as:

$M A X_{H_{i j}} \sum_{i}^{39} \sum_{j}^{4} H_{i j} P_{j} Y_{i j}+\sum_{i}^{39} C_{i} P_{C} Y_{i C}$

Subject to the constraints:

$C_{i}=\bar{A}_{i}-\sum_{j}^{4} H_{i j}$

$H_{i j} \leq \bar{H}_{i j}$

Where $H_{i j}$ is the area of HVC category $j$ planted in province $i, P_{j}$ is the national price of $\mathrm{HVC}$ category $j, Y_{i j}$ is the expected yield of HVC category $j$ in province $i, C_{i}$ is the area planted in cereal rotation in province $i, P_{C}$ is the price of cereal crops, and $Y_{i C}$ is the yield of cereal crops in province $i, \bar{H}_{i j}$ is the limit of land available for HVC category $j$ in province $i$, and $\bar{A}_{i}$ is the total cultivable area in province $i$.

We use gross value of crop production in this model as opposed to net value for two main reasons. First, cost data are extremely difficult to obtain when farming practices are highly diverse, as is the case in Morocco and other developing countries. In such a context, production inputs differ greatly from crop to crop, region to region, and even farmer to farmer. Furthermore, household labor is a key input, but is difficult to value. In contrast, production outputs are readily observable and much easier to value. Since data on gross production are widely available and we intend this model to be applicable in a variety of countries and contexts, we optimize the model based on gross production value.

Second, we use gross value instead of net value to better approach trade and food security questions. Agricultural exports are an important source of foreign exchange for many developing countries. As true self-sufficiency becomes increasingly infeasible and international trade plays an increasingly important role in food security, foreign exchange will become a central piece of any national food security plan (Panagariya 2002). If generating foreign exchange is a policy goal, the role of costs is diminished since inputs are typically domestically produced and paid for using local currency. When the production from these domestic factors is exported and paid for with international currency, the costs of production do not count against the foreign exchange generated.

A final note about our focus on gross production value: while we do not explicitly account for production costs, our model is implicitly constrained by them. The model is couched in historical precedent so that possible national solutions are limited to past crop-specific land allocations within each province. Thus, to the extent that individual farmers have previously chosen to cultivate crops based on expected farm level net returns, our modeling approach reflects these considerations as constraints on economically feasible land allocation by crop category and province. Since HVCs cannot be grown on more land in any province than they have at their historical maxima, the model imposes the implicit constraint that land is only planted with crops for which it is economically viable.

\section{Model limitations}

A simple model like this has several major limitations. The maximization routine solves a problem at a national level, whereas in reality the solution would come from the aggregated decision of millions of extremely heterogeneous and dispersed farmers who live in a world of risk and incomplete markets. Here we address some of these limitations.

The omitted value of crop residue

Livestock is omitted from the model, but we acknowledge its important role in Moroccan farming systems, and throughout the Arab world. Cereal rotations provide complementarities to livestock production through straw and stubble production, which constitute up to $38 \%$ of ruminant diets in Morocco (Guessous 1991; cited in Mrabet 2008). Forage crops also constitute part of the cereal rotation in this model. Forage crops are sold in the market and their prices are incorporated directly into the model. Straw is much less valuable than forage crops, but is still sometimes traded and therefore has a market price. Local market prices, however, vary widely across the country and straw prices are not readily available. A further complication is that many farmers do not participate in straw markets since transport costs are high relative to the value of the product. If farmers do not use straw markets because of prohibitive transport costs, the straw they co-produce with cereals still has an implicit price, but it differs from the market price and is not observable (Magnan 2010).

Valuing crop stubble is more difficult than valuing straw. Markets for crop stubble are not well established, if they exist at all, so prices are not observable. Furthermore, because of incomplete property markets it is unclear how much stubble a farmer can capture from his or her field. Because of these measurement issues, the value of straw and crop stubble is omitted from the model, and cereal rotations in the presence of livestock are consequently undervalued. The magnitude of this bias is difficult to measure, but is an important area of research necessary to understanding crop choice in developing countries. In other work, we are formulating methods to calculate the value of 
crop stubble using in-depth household level data on cereallivestock interactions (Magnan 2010). Accurate estimations for the value of crop residue will allow for a more complete valuation of cereal production, and therefore a more appropriate PPF that accounts for the importance of cereal-livestock mixed farming.

\section{Production lags for permanent crops}

The model does not take into account dynamic revenue streams, and may therefore be biased towards HVCs. For instance, olive trees can take 7 years to bear fruit. For almonds, oranges, cherries, dates, and other trees, there is also a lag between the time the trees are planted and the time they generate revenue. Other HVCs generate revenue after a single season, such as truck crops, sunflowers, and sugar beets and cane. Cereals and legume crops all generate revenue at the end of the first season.

This lag would cause the model to overvalue HVCs since the model does not discount returns from HVCs, nor account for years until a harvest is possible. From a national food security perspective, this bias would be small. Conversion from cereal to HVCs is usually gradual. At the national level, all farmers will not convert at once. At the farm level, farmers will not plant all their crop of a permanent $\mathrm{HVC}$ at once so the plants do not all have to be turned over at once later on. As a result, HVCs are not all productive at the same time, so the period of conversion should be compared to a period of partial productivity, not complete productivity.

The question of conversion from cereal to HVCs at the farm level is more difficult. Farmers may not be able to convert at all because they are not able to sacrifice any cereal revenue in order to wait for HVC revenue, however large it will be, since they lack access to credit. Poorly functioning credit markets can also prevent farmers from making the initial investment in permanent crops, keeping them constrained to annual cereal crops. Programs to help farmers overcome these constraints exist, ${ }^{1}$ and implementation is a question of regional and national policy that is beyond the scope of this paper. However, we recognize that conversion to HVCs may not be feasible at the farm level, even if it is value maximizing at the national level.

\footnotetext{
${ }^{1}$ Several major projects are underway in Morocco to help small farmers convert from cereal to cash crops. In 2007 The Millennium Challenge Corporation signed a contract with the government of Morocco to improve and expand fruit tree production, with expansion aimed at land currently in cereals (http://www.mcc.gov/mcc/countries/ morocco/ma-projects/index.shtml). In a separate effort, the government of Morocco aims to convert 3 million ha of marginal cereal land to cash crop production to help alleviate rural poverty.
}

Other inputs

Ideally, the model would include other scarce inputs besides land. Land is useful for agriculture only if it has water. This model factors in water limitations implicitly by looking at historical area planted, but a more sophisticated model could go much further, if data were available. If we knew how much land could be irrigated in each province, and how much irrigation water was available to be distributed across this land, then the optimization could be solved using more choice variables (land, irrigated land, and irrigation water). Water is a more complicated input than land since returns are non-linear. The researcher would need to have detailed estimations of how water affects yields, or otherwise use ad-hoc minimum water requirements for the cultivation of different crops.

The same arguments for, and issues with, using water in the model also apply to inputs like fertilizer, pesticides, machines, and labor. These inputs can all increase yields and are all scarce. A complete model would allow the social planner to distribute a finite amount of these inputs throughout the country so they are put to best use. As for water, returns to these inputs are non-linear, and interactive, so the data needed to correctly calibrate the model to accommodate these variables would be extremely difficult to obtain.

\section{Risk}

The model we present does not account for risk. We use expected yields based on historical averages for all crops. Rainfed crops, however, experience highly fluctuating yields, particularly in semi-arid regions. A risk-averse social planner (or farmer) may be more interested in maximizing expected utility of value of production rather than expected value of production. If yield and rainfall distributions were calculated then risk could be incorporated into the model, using a utility maximization problem for a risk-averse agent. To parameterize the model the researcher would need information on how bad certain events would be, i.e. a low cereal production year or a low HVC production year.

\section{Barriers to markets}

The model assumes that all farmers and Morocco as a whole are able to sell their HVC production. In reality, production of a good does not ensure the ability to sell it. HVCs are typically cash crops. If individual farmers cannot access marketing chains, the benefits from HVC production will be drastically reduced. If Morocco is not able to export HVCs it will not be able to trade these goods for cereal to address food security concerns. The assumption of perfect 
export and import markets could bias the solution towards HVCs. Barriers to import markets are also a concern. Cereal exporters used export bans to stabilize domestic prices; this has created mistrust towards international markets in cereal importing countries (Anon. 2009a, b). To incorporate imperfect markets, the model could include a constraint on the amount of HVC that can be exported and cereal that can be imported. This would push the optimal solution towards greater cereal production. This type of extension would be very useful if country level trade-off models were to be aggregated into multi-country trade models.

\section{Results}

Production limits and tradeoffs

Using the data on yields and cultivated area described above, we construct a PPF that illustrates the tradeoff between cereal production and HVC production in terms of quantity. At any point on the curve it is impossible to expand production of one without sacrificing production of the other by reallocating land. Because this allocation process is optimized, land that is suitable for crop $\mathrm{X}$ in provinces with relatively high yields is used first. In order to further expand national production of crop $\mathrm{X}$, land that is suitable for crop $\mathrm{X}$ in other less productive provinces is cultivated with crop $\mathrm{X}$ at the expense of another crop. The marginal increase in total production value falls as cultivation of crop X spreads to increasingly less productive provinces (recall that the land in these less productive provinces is still suitable in the sense that crop $\mathrm{X}$ has been grown on the land at some point in the past). Consistent with the underlying notion of a PPF, the heterogeneity of crop yields by province implies specialization of production inputs and gives the PPF its curved shape.

Figure 1 displays the PPF generated by our constrained optimization routine. The solid curve reflects the PPF itself: maximum attainable production of $\mathrm{HVC}$ and cereals. The dashed curve represents the gross production value of HVCs and cereals along the PPF. The gross value of production does not include the value of straw and stubble as animal feed for the reasons discussed earlier. The lone diamond and circle in Fig. 1 represent the expected national production and value, respectively, of HVCs and cereals based on actual $2003^{2}$ crop-specific area allocations. If maximizing the gross value of production is the goal, as specified by the model, then the optimal production point is where the dashed line

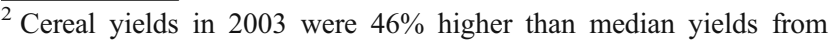
1990 to 2007, and 21\% higher than median yields from 1961 to 2007 (FAO 2009).
}

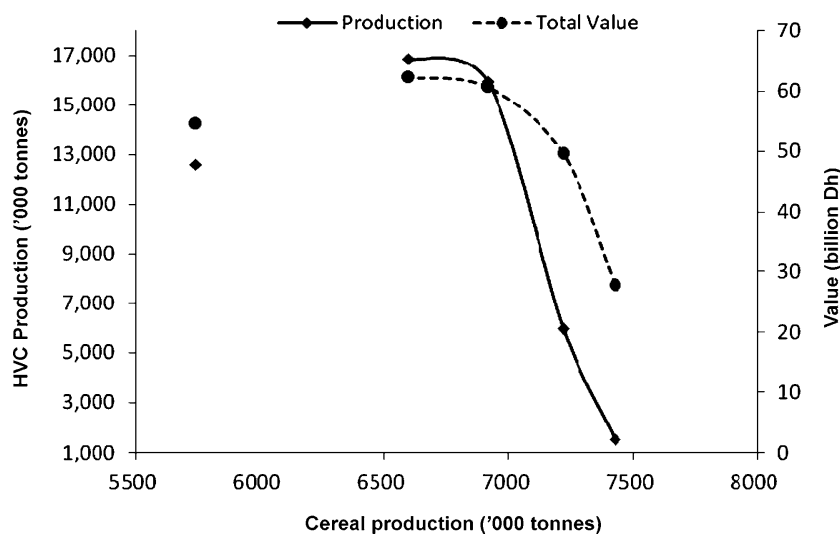

Fig. 1 Production possibilities frontier $(P P F)$ between cereal and HVC production

reaches its peak. In the base case, shown in Fig. 1, the peak of that curve is at its leftmost limit.

To maximize value in the absence of market changes or policy instruments, as much land will be put into HVCs as possible. As further cereal production is imposed on the model, the least productive HVC land is shifted to cereal production first. As more cereal production is imposed, more productive HVC land is shifted to cereal. The last few hectares of land to be taken out of HVCs and put into cereals are the most productive, which is why both the PPF curve (solid) and value curve (dashed) in Fig. 1 become very steep as cereal acreage reaches its maximum.

The most recent sufficiently complete data we have on province level land use and production are from 2003. Using the most conservative assumption of zero convertibility of cereal land to HVC land, we find that $87 \%$ of all possible land for HVC production was used. Of the remaining land that would be available for cereal production, $84 \%$ was used (Fig. 1). This puts 2003 production inside the PPF curve, holding yields constant across years. In relative terms the distance from the PPF is not great, but in absolute terms the shortfall in value and production is substantial: over 8 billion $\mathrm{Dh}^{3}{ }^{3} 630,000 \mathrm{t}$ of cereal, and 4.5 million $t$ of HVCs are foregone by producing inside the curve. If the assumptions of zero convertibility of cereal land to HVCs and zero interchangeability of HVCs within the category are relaxed, the difference is even greater.

Next, we assess the tradeoff gradient between cereal and HVC production, which is the slope of the PPF curve at any point, using a value-less elasticity measure we term Value Tradeoff Elasticity (VTE) being:

$\mathrm{VTE}=\frac{\% \Delta \text { total gross value of production }}{\% \Delta \text { share of total land in cereals }}$

\footnotetext{
3 Over the past several years the Moroccan Dirham (Dh) has varied between 8 and $10 \mathrm{Dh}=\mathrm{US} \$ 1$.
} 
Thus defined, the VTE captures the sensitivity of total gross production value to changes in land allocation between cereals and HVCs. Because constraining the model to different levels of land in cereal production forces the model to reshuffle land optimally between HVCs and cereals, the VTE indicates the value tradeoffs, or implicit costs, of shifting land into cereal production. The absolute value of VTE is increasing as the proportion of land in cereals increases (Fig. 2). This means that the further production moves towards cereals, the more additional value of production is lost for each unit of HVCs converted.

\section{Policy experiments}

A wide variety of policy experiments can be conducted using the model, shedding light on different aspects of the tradeoff countries face between cereal and HVC production. The user can calibrate the model to reflect changes in land availability, prices, yields, and policy objectives.

i) The user can increase flexibility between crops by increasing maximum possible cultivated areas from their historical means. The model also allows the user to increase or decrease total cultivable area.

ii) As evidenced by recent history, prices can change drastically. The model allows the user to test for different sets of crop prices.

iii) Yields can be increased within the model, by crop category and by province, to simulate changes in technology or climate.

iv) Policy goals such as provincial and national production minima and maxima can be imposed on the model to account for objectives other than value maximization, such as self-sufficiency in cereal production.

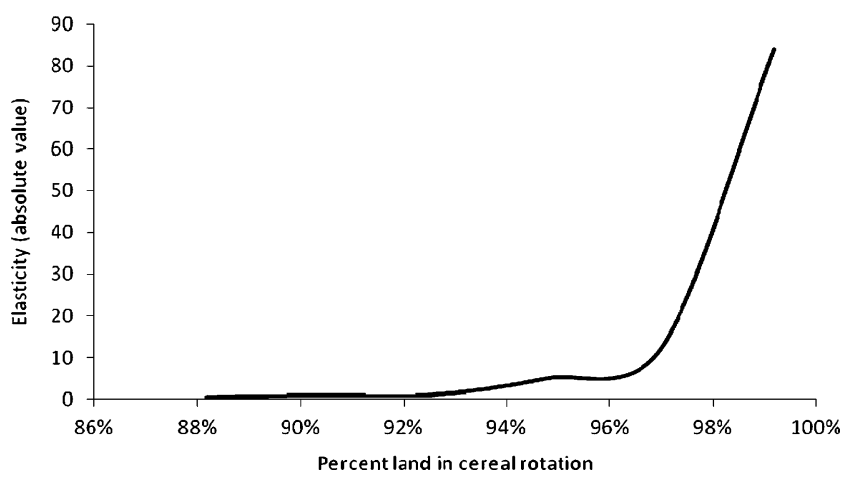

Fig. 2 Value tradeoff elasticity as the percentage of land in cereals increases
Here we show three examples of policy experiments conducted with the model: an increase in land suitable for HVC cultivation, a cereal price shock, and a cereal self-sufficiency policy.

Increase in land suitable for HVC cultivation

Under the plausible assumption that a good deal of land where cereals are produced cannot be used for HVCs because of a lack of irrigation, additional irrigation would allow for conversion of cereal land to HVCs without changing expected HVC yields on the remaining (nonirrigated) cereal land. Additional irrigation could be done on a large scale (dams) or on a small scale (rainwater collection, wells, pumps, etc.). The efficiency of irrigation could also be improved by replacing surface irrigation with targeted irrigation, allowing a wider variety of crops to be grown using less water. Our first simulation will be to allow for land suitable for HVC cultivation to increase by $20 \%$, which is the equivalent of allowing $3.4 \%$ of cereal land to be converted to HVCs.

If we allow for a $20 \%$ increase in HVC land without any expansion of total cropped land, the PPF (solid curve) pivots and bends as shown in Fig. 3, favoring more production of HVCs and increasing overall value of production. The optimal solution after HVC land is expanded includes $112,000 \mathrm{t}$ less cereal production and $3,354,693 \mathrm{t}$ more HVC production. The increase in total value of production is nearly 8.9 billion $\mathrm{Dh}$, and the decrease in subsidy cost to the government is over 8.5 million Dh. We must add that this $20 \%$ expansion can be applied to any HVC, so the highest value ones are chosen for the optimization problem. When all HVC groups are constrained to increase proportionately, the decrease in value is less pronounced.

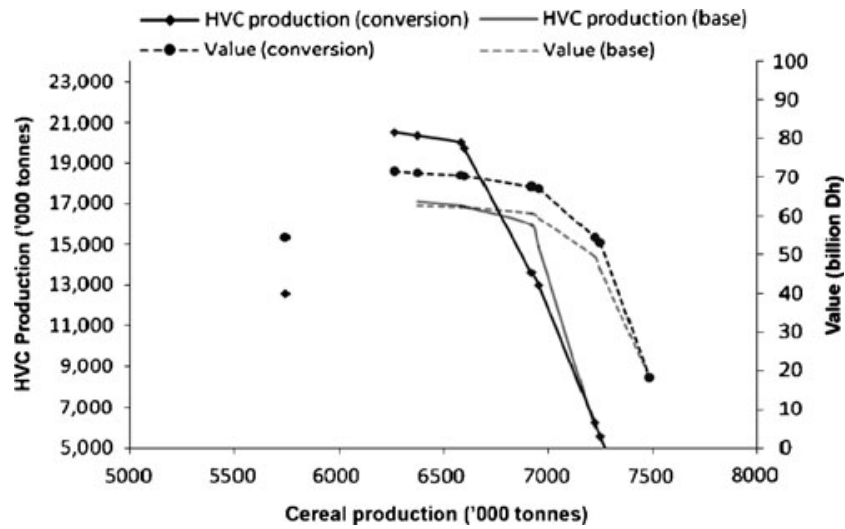

Fig. 3 Production possibilities frontier $(P P F)$ after land suitable for HVC increases 
A cereal price spike

The optimization model uses 2005 prices, when the weighted average of cereal prices in Morocco was 2260 $\mathrm{Dh} / \mathrm{t}$. Since then there has been enormous volatility in prices. At their peak in March 2008, world wheat prices were around 160\% higher than 1 year earlier (FAO 2009). This kind of spike has major implications for the value of different production combinations along the PPF, and thus for the optimal solution. Here we simulate a $150 \%$ increase in cereal price, holding HVC price constant. The PPF (dashed curve) becomes slightly steeper in this case (Fig. 4). Optimal cereal production increases by 472,000 t, or $16 \%$, which is small considering the size of the price spike. This apparent discrepancy is due to the fact that cereals were previously produced only because the land could be used for nothing else. After the price spike, some land that could be used for HVC cultivation is converted to cereal. Even though cereal production increases substantially under a price spike, the cost of the production subsidy to the government would decrease since the world price exceeds the support price. Total government expenditure on cereal, however, would increase dramatically as Morocco is a net importer.

\section{Self-sufficiency in cereals}

The final policy simulation we demonstrate is the implementation of a national minimum production standard to achieve cereal self-sufficiency ${ }^{4}$ in the face of growing domestic demand, as projected by IFPRI (2008). The model is used to maximize the total value of all crops while constrained by domestic demand for cereals. If median yields from 1994 to 2003 are achieved, then Morocco could only reach $85 \%$ cereal self-sufficiency for 2008 .

That is not to say that expected cereal yields cannot be increased (or have not already increased) through more intensive input use or technological change. According to the FAO (2009), median cereal yields during 2004-2007 were $17 \%$ higher than in 1994-2003. With the input data available (1996 Moroccan Agricultural Census), it is not possible to fully understand how input use affects yields, but some insight can be gained. Labor intensity is positively correlated with fruit yields. Irrigation is positively correlated with cereal, legume, and oil crop yields. Land privatization is positively correlated with cereal yields. We will not go so far as to claim causality, although it is likely that more intense input use and better property rights

\footnotetext{
${ }^{0}$ Self-sufficiency in this case is for cereals for food only. The model can easily be altered to consider food plus feed demand.
}

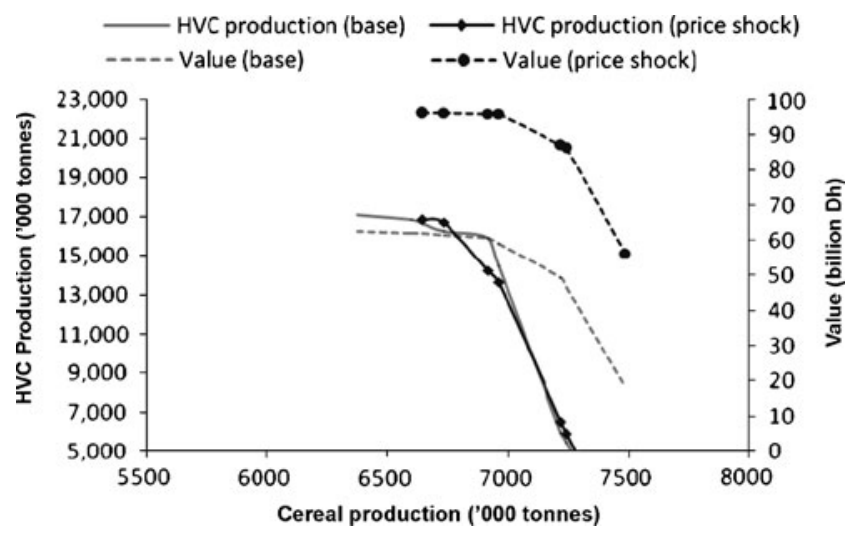

Fig. 4 Production possibilities frontier $(P P F)$ after a cereal price spike

improve yields. If this is true, then yields can be improved through policy and technological change. If yield projections based on agronomic research were available, policy makers could calibrate the model with projected province level yields to investigate the feasibility of future selfsufficiency to meet increasing demand. Since we do not have these projected yields, we choose values that demonstrate how the cost of achieving and maintaining cereal self-sufficiency increases with demand increases.

If cereal yields increased by $30 \%$ above their 1994 2003 median then Morocco could meet projected demand in 2008 and 2009, but not beyond. In order to present a scenario where self-sufficiency is attainable for a number of years, we arbitrarily increase yields by $40 \%$ while holding HVC yields constant. For each year, we estimate the model twice, once maximizing total value, and once maximizing total value subject to producing enough cereal to satisfy domestic demand. We then estimate the implicit cost of meeting cereal self-sufficiency from 2008 until it would no longer be possible, in 2022. In the first few years, from 2008 to 2010 , demand is not a binding constraint and the country produces a small surplus of cereal. $^{5}$ In 2011, however, the surplus no longer exists and demand cannot be met without sacrificing some HVC land and therefore sacrificing total value of agricultural production.

By converting HVC land to cereal production Morocco could remain self-sufficient in cereal until 2022, when all cultivable land would need to be in cereals. Each year between 2011 and 2022, HVC production, HVC value, and total crop value would drop as the country seeks to remain self-sufficient. Over the course of the 11 years, Morocco

\footnotetext{
${ }^{0}$ In reality Morocco is currently a cereal importer, but would not be if provincial yields were brought up to the regional best levels used in two simulations in this paper.
} 
Table 3 Consequences of matching increasing cereal demand

\begin{tabular}{|c|c|c|c|c|c|c|}
\hline Year & $\begin{array}{l}\text { Cereal demand } \\
\left({ }^{\prime} 000 \mathrm{t}\right)\end{array}$ & $\begin{array}{l}\text { Cereal supply } \\
\text { ('000 t) }\end{array}$ & $\begin{array}{l}\text { HVC supply } \\
\text { ('000 t) }\end{array}$ & $\begin{array}{l}\% \text { area in } \\
\text { Cereal }\end{array}$ & $\begin{array}{l}\text { Loss in Value } \\
\text { ('000,000 Dh) }\end{array}$ & $\begin{array}{l}\text { Increase in subsidy costs } \\
(' 000,000 \mathrm{Dh})\end{array}$ \\
\hline 2008 & 7909 & 8159 & 17,072 & $86.5 \%$ & 0 & 0 \\
\hline 2009 & 7998 & 8159 & 17,072 & $86.5 \%$ & 0 & 0 \\
\hline 2010 & 8088 & 8159 & 17,072 & $86.5 \%$ & 0 & 0 \\
\hline 2011 & 8188 & 8188 & 17,046 & $86.8 \%$ & 42 & 22 \\
\hline 2012 & 8299 & 8299 & 16,947 & $87.7 \%$ & 247 & 107 \\
\hline 2013 & 8401 & 8401 & 16,830 & $88.5 \%$ & 520 & 184 \\
\hline 2014 & 8500 & 8500 & 16,076 & $89.6 \%$ & 851 & 260 \\
\hline 2015 & 8616 & 8616 & 13,956 & $90.4 \%$ & 1398 & 348 \\
\hline 2016 & 8738 & 8738 & 13,705 & $92.1 \%$ & 2039 & 442 \\
\hline 2017 & 8899 & 8899 & 10,730 & $93.9 \%$ & 4354 & 565 \\
\hline 2018 & 9002 & 9002 & 9306 & $94.5 \%$ & 6633 & 643 \\
\hline 2019 & 9115 & 9115 & 7681 & $95.4 \%$ & 9743 & 730 \\
\hline 2020 & 9221 & 9221 & 6032 & $96.6 \%$ & 13,924 & 810 \\
\hline 2021 & 9312 & 9312 & 5137 & $97.4 \%$ & 19,475 & 880 \\
\hline 2022 & 9427 & 9427 & 130 & $99.9 \%$ & 43,706 & 967 \\
\hline \multicolumn{5}{|c|}{ Total 2008-2022 } & 102,932 & 5,956 \\
\hline
\end{tabular}

foregoes growing 71.3 million t of HVCs, and 103 billion $\mathrm{Dh}$ after netting out the value of increased cereal production. Assuming that the percentage of cereal production covered by the soft wheat subsidy remains constant under a self-sufficiency program, the total cost of subsidy would also increase with demand, to almost 1 billion Dh in 2022 . The total cost of the subsidy from 2011 to 2022 would be nearly 6 billion Dh more under a self-sufficiency policy than in the unconstrained scenario (Table 3). ${ }^{6}$

In the initial years this policy does not have a large effect on value of production, since only the least productive HVC land is used for cereal cultivation. However, as time passes and demand grows, the land set aside for cereals is of increasingly high potential for HVCs, and the total value of production foregone increases sharply (Fig. 5).

According to our model, unless cereal yields improve dramatically (much more than 40\% over 1994-2003 levels), self-sufficiency in cereals will be a very costly, and eventually impossible, objective. Even if yields do improve enough to achieve self-sufficiency, the opportunity cost of not putting land into HVC cultivation when possible will be tremendous. As Morocco approaches self-sufficiency, the trade-off becomes very steep, and agricultural self-reliance is greatly reduced because of the loss in value of production that could be used for trade.

$\overline{{ }^{0} \text { These values }}$ do not account for discounted future revenues.
Extensions to the self-sufficiency simulation

In addition to increasing food demand, decreases in land availability are also likely, and these decreases could alter the food-security picture in the future. For instance, urban sprawl could reduce the amount of cultivable land a little each year, or decreasing water availability could limit irrigation in the future, decreasing the amount of land suitable for HVC cultivation. We have no indications about how large these changes would be, but the model is flexible enough to allow researchers to simulate the effects of these changes with using their own estimations.

It would be possible to loosen the binding constraint on cereal self-sufficiency while still allowing it to play a role in the model. For instance, instead of maximizing value of

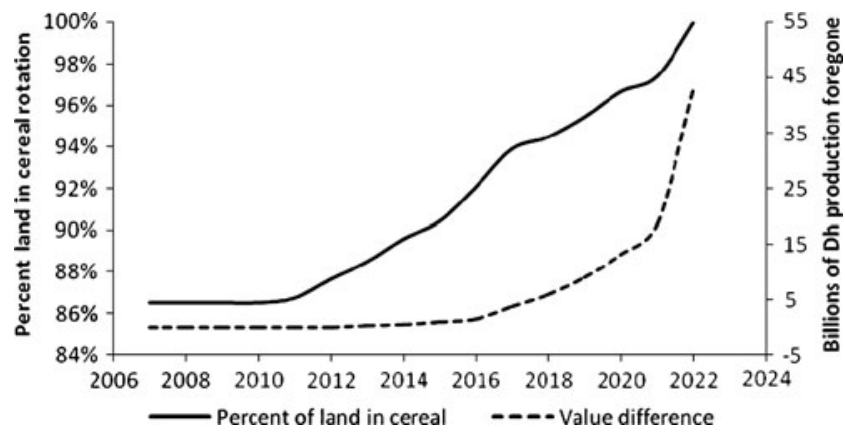

Fig. 5 Land area in HVCs and total value of crops under cereal selfsufficiency 
production while satisfying a self-sufficiency constraint, the social planner could use a utility function that is a joint function of value of production and percentage selfsufficiency. This technique could also be used to incorporate other non-monetary values such as cultural, environmental, or nutritional value of a crop.

\section{Conclusions}

Due to recent high and volatile cereal prices, governments of food importing countries have shown renewed interest in self-sufficiency. However, using policy to push production towards staples would negatively affect agricultural selfreliance, which may ultimately be the more important goal. National food security can be strengthened not only through import substitution (increasing domestic production and reducing imports) but alternatively by generating foreign exchange by encouraging the production of HVCs for export and ensuring the appropriate market channels are open.

Food security implies that all households in the country can afford food. In many ways households face the same dilemma as countries, but at a smaller scale. Since many poor farmers are net buyers of food, they are adversely affected by high staple prices. Potentially, they could counter high prices by increasing staple production. If this cannot be done through intensification, they may need to sacrifice other land, for example land where they grow fruits and vegetables. This would make sense if they do not have access to HVC markets. However, if they do have market access, they could increase their cereal consumption by growing less staple crops and more HVCs, using the resulting income to purchase cereal. This is the strategy recommended by the World Bank's World Development Review (World Bank 2008) and other development organizations. Any national program that aims to increase staple production at the expense of HVC production could threaten both national selfreliance and household food security. Subsidizing farmers to grow cereals, either through deficiency payments or targeted input subsidies, could make cereal farming more lucrative than HVC farming, but this strategy has proved unsustainable in some instances (e.g. Egypt and Saudi Arabia) and can also be against World Trade Organization regulations. HVCs are generally more labor intensive than cereals, so encouraging landowners to grow cereals instead of HVCs could reduce employment opportunities for the landless.

It is difficult to model the trade-offs that shape national food security, especially because of lack of data, in the Arab region and globally. The model we present can be replicated throughout the Arab region and beyond to shed some light on important food security questions: What are the tradeoffs between self-sufficiency in staples and value maximization? How close can countries get to selfsufficiency? What are the implicit costs of attempting to achieve self-sufficiency? We show here that in the case of Morocco the trade-off is very steep. While it would be possible for Morocco to be self-sufficient in cereals with higher yields and conversion of HVC land to cereal production, it would come at a great cost and a reduction in agricultural self-reliance.

Acknowledgments The authors would like to thank Nicholas Pasiecznik and Ajay Varadachary for editorial assistance and four anonymous referees for helpful comments and guidance. Participants at the 2010 Economists' Forum at the World Bank also provided valuable insights. All remaining errors are those of the authors.

Open Access This article is distributed under the terms of the Creative Commons Attribution Noncommercial License which permits any noncommercial use, distribution, and reproduction in any medium, provided the original author(s) and source are credited.

\section{References}

Anonymous (2009a). How to feed the world. The Economist, 21-27 November 2009.

Anonymous (2009b). If words were food, nobody would go hungry. The Economist, 21-27 November 2009

Arab Organization for Agricultural Development (2008). The Arab Agricultural Statistical Yearbook. Khartoum, Sudan: AOAD.

Azzam, A. M. (1991). Food subsidies and market interdependence: the case of the Moroccan soft wheat subsidy. Agricultural Economics, 5, 325-333.

FAO (Food and Agriculture Organization) (2009). FAOStat. Online database. , Rome: FAO. www.faostat.fao.org. Accessed 12 January 2010.

IFPRI (International Food Policy Research Institute) (2008). Projections for the Middle East and North Africa region: outlook for food and feed to 2030. Research Note. Washington: IFPRI.

Magnan, N. (2010). Thee Essays on Technology Choice in Rainfed Cereal-Livestock Systems in Morocco. Ph.D. Dissertation, Department of Agricultural and Resource Economics. Davis, CA USA: University of California, Davis.

Mrabet, R. (2008). No-tillage systems for sustainable dryland agriculture in Morocco. Rabat: Institut National de la Recherche Agricole.

Panagariya, A. (2002). Trade and food security: conceptualizing the linkages. Proceedings of the Conference on Trade, Agricultural Development and Food Security: The Impact of Recent Economic and Trade Policy Reform. 11-12 July 2002, Rome, Italy. Rome: FAO.

Ryan, J., Masri, S., Ibrikçi, H., Singh, M., Pala, M., \& Harris, H. C. (2008). Implications of cereal-based crop rotations, nitrogen fertilization, and stubble grazing on soil organic matter in a Mediterranean-type environment. Turkish Journal of Agriculture and Forestry, 32, 289-297.

World Bank. (2008). World development report 2008: Agriculture for development. Washington: The World Bank. 


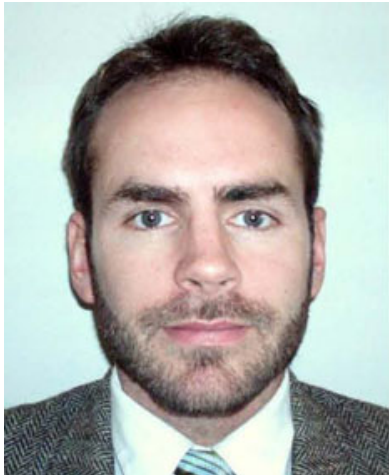

Nicholas Magnan joined IFPRI in 2010 as part of the CGIAR Challenge Program on Climate Change, Agriculture and Food Security. His previous and current research spans the areas of technology adoption, climate change adaptation, sustainable agriculture and agroforestry, drought and pest risk, imperfect markets and property rights, and food security. He received his $\mathrm{Ph} . \mathrm{D}$. in Agricultural and Resource Economics from the University of California, Davis in 2010. While completing his degree he concurrently worked on food security issues in the Middle East and North Africa region as a consultant for the World Bank.

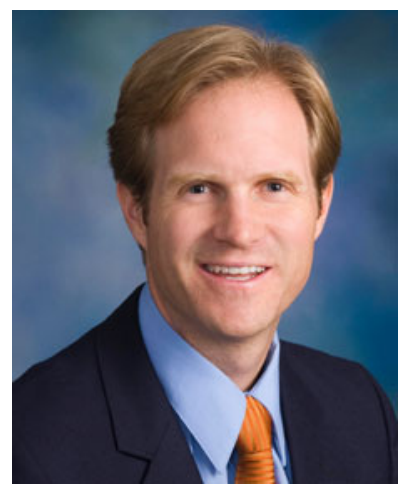

Travis J. Lybbert joined the faculty of the Department of Agricultural and Resource Economics at UC Davis in 2006. Dr. Lybbert earned M.S. and Ph.D. degrees in Applied Economics from Cornell University. Prior to coming to Davis, he was an assistant professor of economics at the Honors College of Florida Atlantic University. Dr. Lybbert conducts research in four interrelated areas of applied economics: risk, poverty dynamics, technology, and environment.

He has worked in North Africa, India, and in the Intellectual Property Division of the World Trade Organization. Among his current research projects, Dr. Lybbert is assessing drought risk, drought coping and vulnerability in Morocco and Burkina Faso; risk and poverty dynamics among Kenyan pastoralists; micronutrient supplements and household welfare in Malawi, Burkina Faso and Ghana; and cell phones and adult literacy in Niger. Dr. Lybbert currently teaches graduate and undergraduate courses in economic development and applied economics.

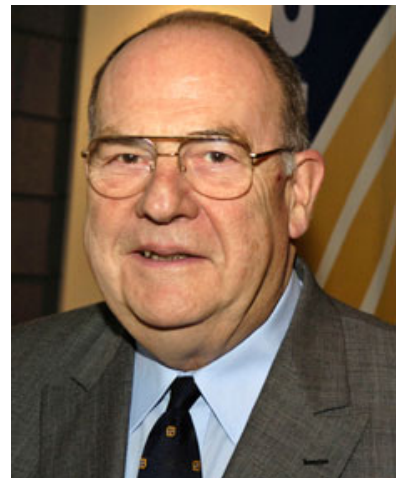

Alex F. McCalla Professor of Agricultural and Resource Economics, Emeritus, and Professor of Management, Emeritus at University of California, Davis.

Alex McCalla spent his academic career at the University of California-Davis where he taught for 28 years and served as Dean of the College of Agricultural and Environmental Sciences (1970-75) and Founding Dean, Graduate School of Management (1979 1981). When he retired from UCD he worked for the World Bank as Director of Rural Development (1994-1999).

Dr. McCalla is best known for his research in international trade. He has been honored by the Agricultural and Applied Economics Association, the Western Agricultural Economics Association and the Canadian Agricultural Economics Society as a Fellow or Distinguished Scholar. He was a founding member and Chair of the International Agricultural Trade Research Consortium. He served as the Chair of the Technical Advisory Committee of the Consultative Group on International Agricultural Research from 1988 to 1994.

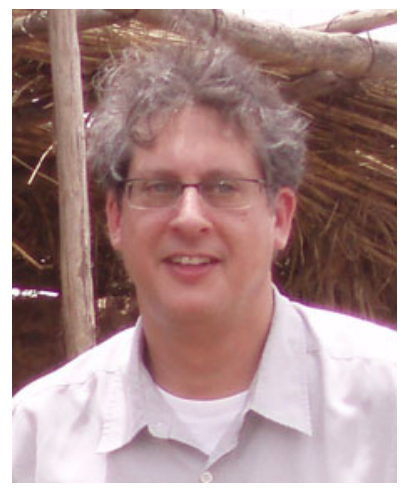

Julian A. Lampietti coordinates the Agriculture and Rural Development Program in the Middle East and North Africa Region of the World Bank. His current responsibilities include strategy and business development as well as program management. The focus of his current work program is on food security in Arab countries, climate change adaptation in agriculture, food supply chains, and public-private partnerships in marketing. Julian has a B.S. in

Agriculture from Rutgers University, an M.S. in Resource Economics from Duke University, and a Ph.D. in Public Policy from the University of North Carolina at Chapel Hill. 